\title{
EDITORIAL
}

\section{Salud Pública de México: evolución de una idea}

$E^{n}$ el verano de 1959, siendo los doctores José Alvarez Amézquita, secretario de Salubridad y Asistencia, y Miguel E. Bustamante, subsecretario de Salubridad, nació la revista Salud Pública de México.

En un principio, la publicación constituyó un esfuerzo por reanudar las actividades regulares de difusión de la situación sanitaria mexicana, iniciadas casi 120 años atrás con la edición del Boletin del Consejo Superior de Salubridad del Distrito Federal, que editaba el Consejo del mismo nombre. En 1892, el Consejo Superior de Salubridad retomó esta publicación, la convirtió en revista de carácter nacional y fundó el Boletin del Consejo Superior de Salubridad. Este boletín, sin embargo, dejó de circular un año después y fue hasta 1916 cuando, en pleno movimiento armado, reinició sus actividades. A partir de 1918 la publicación adoptó, sucesivamente, los nombres de Boletín del Departamento de Salubridad Pública, Boletín del Departamento de Salud Pública, Salubridad, Boletín de Salubridad e Higiene, nuevamente Boletín del Departamento de Salubridad Pública y Salubridad y Asistencia. Estas publicaciones, que fungieron como órganos oficiales de la Secretaría de Salubridad y Asistencia, funcionaron regularmente hasta 1948, para dejar de publicarse por 11 años.

Las publicaciones mencionadas estuvieron marcadas por el tipo de salud pública practicada en la primera mitad del siglo, representada por el Código Sanitario Panamericano, aceptado por los países de la región durante la VII Conferencia Sanitaria Panamericana, realizada en La Habana, en junio de 1924. Este Código se proponía prevenir la propagación internacional de infecciones, estimular y adoptar medidas cooperativas encaminadas a impedir la introducción de enfermedades en los territorios de los gobiernos signatarios, uniformar la recolección de datos estadísticos relativos a la morbilidad en dichos países, estimular el intercambio de información que puediera mejorar la sanidad pública, y uniformar las medidas empleadas en los puntos de entrada para evitar la introducción de enfermedades transmisibles. Desde principios del siglo y hasta bien entrados los años treinta, el énfasis preventivo y vigilante estuvo encaminado a la detección de cólera, fiebre amarilla, peste bubónica, tifus exantemático, meningitis cerebroespinal, encefalitis letárgica, poliomielitis aguda, gripe epidémica y fiebre tifoidea. Su detección obligaba a la inmediata puesta en marcha de medidas sanitarias para impedir la transmisión y la propagación de cualesquiera de dichas enfermedades. Los esfuerzos realizados en materia de control y prevención dieron frutos: ejemplos de ello fueron la erradicación de la fiebre amarilla y la viruela, la desaparición del cólera y el abatimiento del tifo epidémico.

En 1959, nació Salud Pública de México. En el editorial de su primer número, el titular de la Secretaría de Salubridad definió a la revista como un órgano de difusión técnica que tenía el propósito de "generalizar los conocimientos de medicina entre los trabajadores de los diferentes niveles de esa dependencia". A partir de esa idea inicial, Salud Pública de México ha experimentado una paulatina y firme evolución, al transformarse en un medio privilegiado de comunicación de la investigación científica que se realiza en México y otros países de América Latina, en los distintos campos de la salud pública.

Inicialmente, Salud Pública de México incorporó en sus páginas trabajos sobre administración sanitaria, educación higiénica, epidemiología, higiene mental, saneamiento del medio, medicina general y notas nacionales e internacionales sobre salud pública. Anualmente, además, publicaba el Informe de la Secretaría y, a partir de 1964, en la llamada Sección Legislativa, los principales decretos y disposiciones en materia sanitaria. Algunas publicaciones que forma- 
ron parte de la revista fueron el Boletín Epidemiológico y la Revista del Instituto de Salubridad y Enfermedades Tropicales, publicados durante 27 años.

A estas alturas de su historia, Salud Pública de México presentaba características múltiples: era una revista académica, un boletín de vigilancia epidemiológica y un órgano que daba cuenta de las actividades de la Secretaría del ramo. Con el propósito de insertarla en un marco institucional que permitiera su transición hacia una revista más académica, a partir de abril de 1985, la Escuela de Salud Pública de México se hizó responsable de su edición.

Una de las acciones encaminadas a lograr dicho objetivo fue la creación de la sección "Investigaciones en Salud Pública", a partir del número de julio-agosto de 1985. Desde esa fecha, la vocación académica de la revista comenzó a definirse cada vez más. En 1987, debido a un proceso de renovación de las actividades de la Secretaría de Salud y con el apoyo expreso de su Consejo Editorial la revista inició una nueva época. Decidió renovar su imagen, ampliar su Comité Editorial, abrir nuevas secciones, formalizar su proceso de arbitraje. Asismismo, introdujó normas editoriales internacionales, solicitó su incorporación a diversos y prestigiados índices, y reorganizó su proceso de oferta y distribución. El buen desempeño que tuvo Salud Pública de México lo hicieron explícito, entre otros, el Boletín de la Oficina Sanitaria Panamericana y el Grupo de Editores de Revistas Biomédicas de la Academia Nacional de Medicina. La "nueva época" de la revista se tradujo en el reforzamiento de su contenido científico. La importante tarea de difundir la información epidemiológica y las actividades de la Secretaría de Salud quedó en manos del Boletín de la Dirección General de Epidemiología y del Boletín de la Secretaría de Salud, respectivamente.

Esta evolución cualitativa de órgano de difusión de las instancias sanitarias gubernamentales a instrumento de comunicación de la investigación científica más relevante en su campo realizada en México es un reflejo del desarrollo de la práctica de la salud pública nacional y mundial, y del progreso de su enseñanza e investigación. En el primer número, publicado hace cuarenta años, los contenidos principales de la revista hicieron referencia a la situación epidemiológica de cuatro de las más importantes causas de muerte en el país (paludismo, rabia, tuberculosis pulmonar y malaria), poniendo énfasis en los aspectos técnicos de los programas que para su erradicación había diseñado el gobierno mexicano. En los últimos años, en cambio, las colaboraciones han dado cuenta de los resultados de la investigación realizada en varios de los terrenos de mayor importancia a nivel mundial, sin abandonar el análisis de los problemas sanitarios relevantes en México, ahora representados por las enfermedades crónicas, las lesiones, la salud mental y la reforma del sistema de salud. Los aportes sobre el desarrollo metodológico y conceptual de la salud pública tampoco han sido extraños en los números recientes. Se han abordado, cada vez con mayor frecuencia, aspectos destacados de la investigación de frontera, documentándose asuntos relacionados con la sociología y la antropología médicas, la economía de la salud, la administración hospitalaria y la definición de políticas sanitarias, por ejemplo. La revista también ha promovido la incorporación de los desarrollos instrumentales más avanzados en el campo de la epidemiología, publicando artículos de excelencia en las áreas de la nutrición, la salud reproductiva y la salud ambiental. Las bases biológicas de la salud pública han fortalecido su presencia mediante el análisis de temas relacionados con la investigación experimental en los campos de la resistencia bacteriana, la inmunidad y la elaboración de vacunas, entre otros. La comprensión de la dinámica $\mathrm{y}$ tendencias de las enfermedades emergentes y reemergentes, como el SIDA, el cólera y la tuberculosis, son desde hace varios años tema de intenso debate en las páginas de la revista.

Actualmente, Salud Pública de México es considerada una de las publicaciones científicas de excelencia en su campo, de Iberoamérica. Está indexada en diez índices bibliográficos en todo el mundo y se encuentra directamente disponible en línea a través de la INTERNET. De esta manera, ha contribuido a formar un grupo cada vez más amplio de lectores interesados en los problemas sanitarios del país y la región.

\footnotetext{
* Editor de Sociomedicina de Salud Pública de México.

‡ Editor Ejecutivo de Salud Pública de México.
} 